\title{
Effect of accelerated corneal crosslinking on ocular response analyzer waveform-derived parameters in progressive keratoconus
}

\author{
Efeito do crosslimking corneano acelerado nos parâmetros \\ derivados da forma de onda do analisador de resposta ocular \\ no ceratocone progressivo
}

Mehmet Murat Uzel', Mustafa Koc', Cigdem Can’', Sibel Polat', Pelin Yılmazbaș', Dilek Ileri

1. Ophthalmology Department, Ulucanlar Eye Training and Research Hospital, Ankara, Turkey.

\begin{abstract}
Purpose: To evaluate the effect of accelerated corneal crosslinking on corneal biomechanics with an ocular response analyzer in patients with progressive keratoconus. Methods: In this retrospective study, 50 eyes of 45 patients with progressive keratoconus who underwent accelerated corneal crosslinking were evaluated with ocular response analyzer waveform parameters before and one year after corneal crosslinking. Paired two-tailed Student's t-test was performed to compare the parameters before vs. after corneal crosslinking. Results: Mean patient age was $17.6 \pm 3.6$ (range 9-25) years. A significant increase was observed in $\mathrm{p} 1$ area, $\mathrm{p} 2$ area, h2, and dive2 values. No significant difference in corneal hysteresis, corneal resistance factor, or other waveform-derived parameters was observed at one year postoperatively. Conclusion: For estimating the effect of accelerated corneal crosslinking on corneal biomechanics, parameters such as p1 area, p2 area, h2, and dive2 are more sensitive than corneal hysteresis and corneal resistance factor. These results may help us to find out which corneal crosslinking method is most effective for stiffening the cornea.
\end{abstract}

Keywords: Keratoconus; Cornea/physiopathology; Corneal crosslinking; Corneal hysteresis; Diagnostic techniques, ophthalmological

RESUMO | Objetivo: Avaliar o efeito do cross-linking corneano acelerado na biomecânica corneana com analisador de resposta ocular em pacientes com ceratocone progressivo. Métodos: Neste

Submitted for publication: October 5, 2017

Accepted for publication: May 19, 2018

Funding: No specific financial support was available for this study.

Disclosure of potential conflicts of interest: None of the authors have any potential conflicts of interest to disclose.

Corresponding author: Mehmet Murat Uzel.

Ulucanlar Eye Training and Research Hospital. 06780, Altindag-Ankara, TURKEY E-mail: drmuratuzel@yahoo.com

Approved by the following research ethics committee: Numune Research and Training Hospital (\#E15-681). estudo retrospectivo, 50 olhos de 45 pacientes com ceratocone progressivo submetidos à cross-linking corneano acelerado foram avaliados com os parâmetros da forma de onda do analisador de resposta ocular antes e um ano após o tratamento com cross-linking corneano. O teste t de Student pareado bicaudal foi realizado para comparar os parâmetros antes e depois do cross-linking corneano. Resultados: A média de idade dos pacientes foi de 17,6 \pm 3,6 (variação de 9 a 25) anos. Um aumento significativo foi observado nos valores de p1area, p2area, h2 e dive2. Nenhuma diferença significativa foi encontrada na histerese da córnea, fator de resistência da córnea ou outros parâmetros derivados da forma de onda foi observada em um ano de pós-operatório. Conclusão: Para estimar o efeito do cross-linking corneano acelerado na biomecânica corneana, parâmentros como p1area, p2area, h2 e dive2 são mais sensíveis que histerese da córnea e fator de resistência corneana. Esses resultados podem nos ajudar a descobrir qual método cross-linking corneano é mais eficaz no enrijecimento da córnea.

Descritores: Ceratocone; Córnea/fisiopatologia; Cross-linking corneano; Histerese da córnea; Técnicas de diagnóstico oftalmológico

\section{INTRODUCTION}

Keratoconus is a degenerative disease that causes the steepening of the cornea and progressive corneal thinning, leading to the deterioration of visual quality and irregular astigmatism $^{(1)}$. Histopathological changes to the stroma result in the loss of biomechanical strength of the cornea, which leads to ectasia ${ }^{(2)}$. Corneal crosslinking (CXL) is the only treatment that specifically targets biomechanical weakness and may halt the progression of keratoconus. During the conventional corneal CXL protocol, $3 \mathrm{~mW} / \mathrm{cm}^{2}$ ultraviolet-A (UVA) light is applied for $30 \mathrm{~min}^{(3)}$. Accelerated corneal CXL appears to shorten the duration 
of the procedure. According to the Bunsen-Roscoe reciprocity law, the effect of treatment is similar when the duration and intensity of illumination are changed, while total energy is conserved (accelerated corneal $\mathrm{CXL})^{(4)}$. Experimental and clinical evidence show that, in terms of ensuring a safety profile with biomechanical stability, the accelerated corneal CXL protocol is equivalent to the standard protocol ${ }^{(4-6)}$.

The Ocular Response Analyzer (ORA, Reichert Ophthalmic Instruments, Depew, NY) may be used to measure the corneal hysteresis $(\mathrm{CH})$ and the corneal resistance factor (CRF) to evaluate the biomechanical properties of the cornea in vivo(7). Studies have shown that the CRF and the $\mathrm{CH}$ are significantly reduced in patients with keratoconus ${ }^{(8,9)}$. Although CXL has been shown to stabilize corneal biomechanics ex vivo(10-12), this improvement in $\mathrm{CRF}$ and $\mathrm{CH}$ levels has not been demonstrated in vivo $^{(13,14)}$. Numerous studies show that these second-generation parameters are more sensitive than the CRF and the $\mathrm{CH}$ in differentiating early-stage keratoconus from the normal cornea ${ }^{(15-17)}$. The new ORA software provides waveform-derived parameters and a more detailed analysis of the corneal deformation signal. Similarly, biomechanical changes undetectable with $\mathrm{CRF}$ and $\mathrm{CH}$ after conventional corneal CXL have been shown to be detectable with the new ORA software ${ }^{(14,18,19)}$. To our knowledge, no study in the literature evaluates biomechanical changes after accelerated corneal CXL with waveform-derived parameters. However, the ability to detect the extent of the biomechanical changes in the cornea after corneal CXL might allow for the optimization of the protocol. The purpose of our study is to assess the effect of accelerated CXL on corneal biomechanics using ORA waveform-derived parameters.

\section{METHODS}

This study is a non-randomized, retrospective clinical study. It was performed at the Ulucanlar Eye Training and Research Hospital during the period from December 2013 through June 2015. The study protocol was approved by the ethics committee of Ankara Numune Research and Training Hospital according to the Declaration of Helsinki. Written consent was obtained from adults and parents of children, after a necessary briefing and before performing CXL.

Patients with progressive keratoconus were included in this study. Progression was defined as an increase of 1.0 diopter (D) in the maximum keratometry value over the past three months in children and over the past six months in adults. The exclusion criteria included previous anterior segment surgery, ocular surface problems, corneal scars, and repeated corneal CXL. ORA measurements, topographic findings (Pentacam HR, Oculus OptikgeräteGmbH), biomicroscopic findings, uncorrected and corrected distance visual acuity (UDVA and CDVA), and refraction measurements were evaluated preoperatively and 12 months postoperatively. All the measurements were obtained by the same (blinded) technician. The average of three consecutive measurements was used for each parameter. Both UDVA and CDVA were recorded using a Snellen chart. Values were later converted to logarithm of minimum angle of resolution (logMAR) values.

The ORA is a modified non-contact pneumotonometer that alters corneal curvature via an air pulse and measures aspects of the corneal biomechanical response during an air-puff perturbation. Changes in corneal curvature are evaluated by analyzing the intensity of light reflected by the cornea. As air pressure is gradually increased during each measurement, the cornea begins to flatten. The first applanation occurs when the level of light reaching the detector is at its maximum (peak $1=\mathrm{p} 1$ ). The cornea continues to collapse with increased air pressure and becomes concave at maximum pressure. When this flow of air symmetrically reduces air pressure, the cornea moves outward again, and the second applanation occurs (peak $2=\mathrm{p} 2$ ). This process may be depicted using two plots: an applanation curve and an air pressure curve (Figure 1). The difference b etween the two applanation pressures yields the $\mathrm{CH}$ value, which indicates the cornea's degree of viscoelasticity. The CRF is another parameter indicative of corneal viscoelasticity and is obtained via regression analysis of applanation pressu-
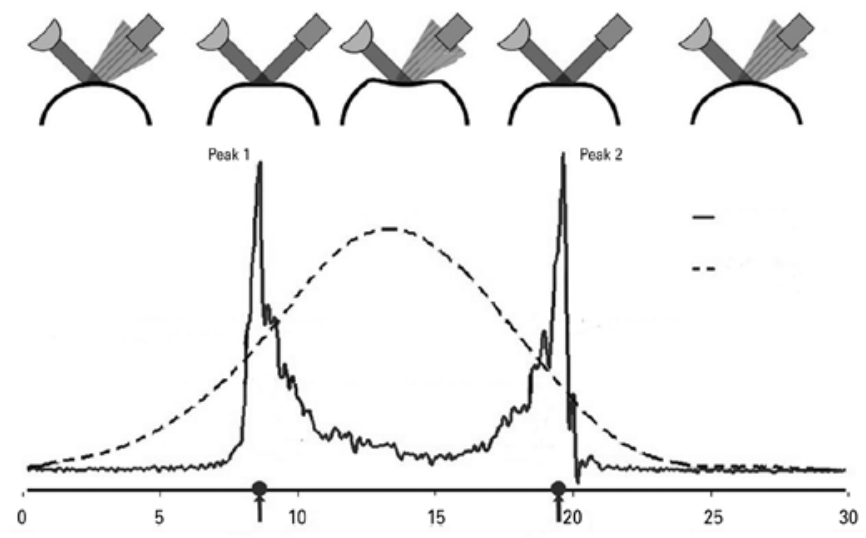

Figure 1. Peak 1 and Peak 2 in ocular response analyzer 
res and correlates maximally with corneal thickness ${ }^{(7)}$ (Figure 2). The manufacturer has recently developed new ORA software (version 2.04), which provides 37 new parameters calculated based on the ORA signal waveform. Table 1 describes these second-generation parameters.

\section{Surgical technique}

Corneal CXL was performed in the operating room with the patient under topical anesthesia with $0.5 \%$



Figure 2. Comparison of corneal hysteresis $(\mathrm{CH})$, corneal resistance factor (CRF), central corneal thickness corrected $\mathrm{CRF}$ and $\mathrm{CH}$ after $\mathrm{CXL}$ treatment. proparacaine hydrochloride eye drops. Using a smooth spatula, the epithelium was removed from the $8.0-\mathrm{mm}$ treatment zone. Iso-osmolar riboflavin solution (Merribo; Meran Tıp, Turkey, with dextran, $2 \mathrm{ml} \mathrm{1 \% )} \mathrm{was} \mathrm{instilled}$ in the cornea every two minutes for $30 \mathrm{~min}$. Ultrasound pachymetry (UP-1000, Nidek Co. Ltd.) was performed next. If the corneal thickness was less than $400 \mu \mathrm{m}$, one drop of hypoosmolar riboflavin solution (Merribo; Meran Tıp, Turkey, without dextran, $300 \mathrm{mOsmol} / \mathrm{L}$ ) was instilled in the cornea (every $20 \mathrm{~s}$ for two minutes). Pachymetry was repeated until the cornea had swollen to thickness $>400 \mu \mathrm{m}$. The CXL system exposes the cornea to 370-nm UVA light (Apollon Cross-linking System, Meran Tip, Turkey) for $10 \mathrm{~min}$ at an irradiance level of $9 \mathrm{~mW} / \mathrm{cm}^{2}$. During the UVA irradiation, riboflavin solution is continually instilled to maintain the corneal saturation balance. At the end of the procedure, the cornea is irrigated with cold water, and a bandage contact lens was applied to minimize the pain.

\section{Statistical analysis}

As a result of a priori power analysis via PASS 11 (Power and Sample Size Calculation Software, Version 11), we decided to enroll at least 45 eyes in the study. We enrol-

Table 1. Description of waveform-derived biomechanical parameters of ocular response analyzer

\begin{tabular}{|c|c|c|}
\hline Parameters & Upper $75 \%$ peak parameters & Upper $50 \%$ peak parameters \\
\hline $\begin{array}{l}\text { Area } \\
\text { (Areas under peak } 1 \text { and peak } 2 \text { ) }\end{array}$ & $\mathrm{p} 1$ area, $\mathrm{p} 2$ area & $\mathrm{p} 1$ area $1, \mathrm{p} 2$ area 1 \\
\hline $\begin{array}{l}\text { Height } \\
\text { (Heights of peak1 and peak 2) }\end{array}$ & h1, h2 & h11, h21 \\
\hline $\begin{array}{l}\text { Width } \\
\text { (Base widths of peak1 and peak 2) }\end{array}$ & w1, w2 & w11, w21 \\
\hline $\begin{array}{l}\text { Aspect Ratio } \\
\text { (Height / width ratios of peak1 and peak 2) }\end{array}$ & aspect1, aspect2 & aspect11, aspect 21 \\
\hline $\begin{array}{l}\text { Slope } \\
\text { (Base to peak value of peak1 and peak 2) }\end{array}$ & $\begin{array}{l}\text { uslope1, dslope1, } \\
\text { uslope2, dslope2 }\end{array}$ & $\begin{array}{l}\text { uslope } 11 \text {, dslope } 11, \\
\text { uslope21, dslope } 21\end{array}$ \\
\hline $\begin{array}{l}\text { Slew Rate } \\
\text { (Aspect ratio of dive } 1 \text { and dive 2-maximum single step increase rise of peak } 1 \text { and peak 2) }\end{array}$ & slew1, slew2, mslew1, mslew2 & - \\
\hline $\begin{array}{l}\text { Path } \\
\text { (Absolute value of path length around peak } 1 \text { and peak 2) }\end{array}$ & path1, path2 & path11, path21 \\
\hline $\begin{array}{l}\text { Irregularity } \\
\text { (Degree of non-monotonicity of rising and falling edges of peak } 1 \text { and peak 2) }\end{array}$ & aindex, bindex & - \\
\hline $\begin{array}{l}\text { Dive } \\
\text { (Absolute value of monotonic decrease on downslope part of peak } 1 \text { and peak 2) }\end{array}$ & dive1, dive 2 & - \\
\hline $\begin{array}{l}\text { High Frequency } \\
\text { (High frequency noise in region between peaks) }\end{array}$ & aplhf & - \\
\hline
\end{tabular}


led 50 eyes, resulting in study power of $89.2 \%$. Central corneal thickness corrected $\mathrm{CH}(\mathrm{ccCH})$ and CRF (ccCRF) calculation methodology have been reported elsewhere ${ }^{(20)}$. SPSS software, version 20 (IBM, Armonk, NY) was used to perform the statistical analysis. To control the potentially confounding effect of CCT, linear regression was applied to other ORA waveform parameters. Transformed CRF (DifCRF) and $\mathrm{CH}$ (DifCH) were computed as the difference between measured and CCT-predicted CRF and $\mathrm{CH}$, respectively, for each observation in both of the groups. Pearson correlation coefficient was used to evaluate the correlations among Kmax, elevation anterior, elevation posterior, corneal thickness, and ORA parameters. Paired two-tailed Student's t-test was performed to compare the parameters before vs. after CXL. In multiple comparisons, a correction of the significance level was performed according to the Bonferroni method. For 37 tests comparing the measurements obtained before vs. after CXL, an adjusted p-value of $0.05 / 37=0.0013$ was considered significant.

\section{RESULTS}

The study included 50 eyes from 45 patients ( 19 males, 26 females) with mean age of $17.6 \pm 3.6$ (range 9-25) years. Table 2 presents changes in visual acuity, refraction, and maximum keratometry at one year postoperatively after corneal CXL. Significant improvements in UDVA (0.17 logMAR), CDVA (0.25 logMAR), spherical refraction (1.29 D), cylindrical refraction (1.1 D), and maximum keratometry $(1.99 \mathrm{D})$ were evident $(p<0.001$ for all).

Table 3 presents the changes in corneal biomechanic parameters after accelerated corneal CXL. Significant in-

Table 2. Preoperative and 1-yr postoperative results for visual acuity, refraction, corneal thickness, and maximum keratometry

\begin{tabular}{|c|c|c|c|}
\hline $\begin{array}{l}\text { Parameters } \\
\text { (range) }\end{array}$ & $\begin{array}{l}\text { Preoperative } \\
n=50\end{array}$ & $\begin{array}{c}\text { First year } \\
n=50\end{array}$ & p \\
\hline UDVA (logMAR) & $\begin{array}{c}0.67 \pm 0.24 \\
(1.4-0.4)\end{array}$ & $\begin{array}{c}0.50 \pm 0.22 \\
(1.2-0.2)\end{array}$ & 0.0001 \\
\hline CDVA (logMAR) & $\begin{array}{c}0.58 \pm 0.22 \\
(1.3-0.4)\end{array}$ & $\begin{array}{c}0.33 \pm 0.23 \\
\quad(1.1-0.2)\end{array}$ & 0.0001 \\
\hline Spherical refraction (D) & $\begin{array}{l}-5.28 \pm 2.22 \\
(-2.00 /-11.00)\end{array}$ & $\begin{array}{l}-3.99 \pm 2.32 \\
(-1.75 /-11.00)\end{array}$ & 0.0001 \\
\hline Cylindrical refraction (D) & $\begin{array}{l}-5.89 \pm 3.91 \\
(-1.50 /-10.50)\end{array}$ & $\begin{array}{l}-4.79 \pm 3.40 \\
(-1.00 /-9.75)\end{array}$ & 0.0001 \\
\hline Maximum keratometry (D) & $\begin{array}{l}57.63 \pm 4.97 \\
(48.50-71.10)\end{array}$ & $\begin{array}{c}55.64 \pm 3.68 \\
(47-65)\end{array}$ & 0.0010 \\
\hline СCT & $\begin{array}{c}461.26 \pm 37.38 \\
(402-544)\end{array}$ & $\begin{array}{c}452.53 \pm 34.26 \\
(392-534)\end{array}$ & 0.0001 \\
\hline
\end{tabular}

UDVA $=$ uncorrected distance visual acuity; $C D V A=$ corrected distance visual acuity; $\log M A R=$ logarithm of the minimal angle of resolution; $D=$ diopter; $C C T=$ central corneal thickness. ${ }^{*} \mathrm{P}<0.05$.
Table 3. Corneal hysteresis, corneal resistance factor, and waveformderived parameters of baseline and first year after accelerated corneal crosslinking

\begin{tabular}{|c|c|c|c|}
\hline Parameters & Preoperative $n=50$ & First year $n=50$ & $\mathbf{p}$ \\
\hline $\mathrm{CH}$ & $8.28 \pm 1.45$ & $8.19 \pm$ & 0.7780 \\
\hline CRF & $6.96 \pm 1.26$ & $6.42 \pm$ & 0.1050 \\
\hline $\mathrm{CH}-\mathrm{CRF}$ & $1.32 \pm 0.84$ & $1.31 \pm 0.74$ & 0.9600 \\
\hline DifCH & $-0.19 \pm 1.31$ & $-0.04 \pm$ & 0.2670 \\
\hline DifCRF & $-0.17 \pm 1.10$ & $-0.05 \pm$ & 0.1210 \\
\hline p1 area & $1662.50 \pm 686.80$ & $2097.50 \pm 588.60$ & 0.0001 \\
\hline p2 area & $1004.40 \pm 437.50$ & $1434.40 \pm 347.80$ & 0.0001 \\
\hline p1 area1 & $687.10 \pm 305.20$ & $716.60 \pm 273.60$ & 0.4340 \\
\hline p2 area1 & $410.90 \pm 193.20$ & $444.90 \pm 154.00$ & 0.2230 \\
\hline h1 & $177.60 \pm 77.00$ & $186.70 \pm 56.90$ & 0.4460 \\
\hline h2 & $131.90 \pm 54.90$ & $181.30 \pm 51.00$ & 0.0001 \\
\hline h11 & $118.40 \pm 51.30$ & $123.10 \pm 37.90$ & 0.6040 \\
\hline h21 & $87.90 \pm 36.60$ & $94.20 \pm 34.00$ & 0.3450 \\
\hline w1 & $24.13 \pm 5.92$ & $25.28 \pm$ & 0.3930 \\
\hline w2 & $21.04 \pm 9.67$ & $22.15 \pm 7.01$ & 0.5320 \\
\hline w21 & $9.91 \pm$ & $12.46 \pm$ & 0.0060 \\
\hline w11 & $12.17 \pm 3.96$ & $14.71 \pm$ & 0.0060 \\
\hline aspect1 & $8.10 \pm 4.36$ & $8.14 \pm 2.91$ & 0.9060 \\
\hline aspect2 & $7.75 \pm 5.01$ & $7.96 \pm$ & 0.8900 \\
\hline aspect11 & $11.03 \pm 6.12$ & $12.71 \pm 4.23$ & 0.0700 \\
\hline aspect21 & $11.37 \pm 8.68$ & $12.77 \pm 7.05$ & 0.4320 \\
\hline uslope1 & $33.47 \pm 19.88$ & $38.96 \pm 13.28$ & 0.0490 \\
\hline uslope2 & $38.64 \pm 26.05$ & $39.71 \pm 21.66$ & 0.7990 \\
\hline dslope1 & $11.38 \pm 6.62$ & $13.68 \pm$ & 0.0180 \\
\hline dslope2 & $9.84 \pm 6.66$ & $10.53 \pm \quad 6.00$ & 0.7000 \\
\hline uslope11 & $32.93 \pm 20.90$ & $34.06 \pm 13.31$ & 0.6620 \\
\hline uslope21 & $32.46 \pm 25.79$ & $34.63 \pm 16.29$ & 0.5820 \\
\hline dslope11 & $17.52 \pm 10.78$ & $19.68 \pm 7.91$ & 0.1470 \\
\hline dslope21 & $16.92 \pm 13.97$ & $19.47 \pm 12.25$ & 0.2960 \\
\hline slew1 & $34.26 \pm 19.42$ & $35.43 \pm 13.42$ & 0.6390 \\
\hline slew2 & $39.88 \pm 25.11$ & $41.36 \pm 20.44$ & 0.7230 \\
\hline mslew1 & $55.12 \pm 27.00$ & $56.38 \pm 17.87$ & 0.7880 \\
\hline mslew2 & $54.75 \pm 27.68$ & $57.16 \pm 27.69$ & 0.7450 \\
\hline path1 & $22.62 \pm 5.19$ & $23.34 \pm 5.86$ & 0.587 \\
\hline path2 & $25.42 \pm 7.29$ & $27.17 \pm$ & 0.3030 \\
\hline path11 & $33.01 \pm 8.07$ & $44.08 \pm 8.70$ & 0.0050 \\
\hline path21 & $36.87 \pm 11.39$ & $37.49 \pm 12.32$ & 0.8190 \\
\hline aindex & $8.46 \pm 1.98$ & $8.87 \pm 2.24$ & 0.4770 \\
\hline bindex & $8.40 \pm 1.99$ & $8.91 \pm 2.44$ & 0.2540 \\
\hline dive1 & $156.20 \pm 79.10$ & $163.20 \pm 60.50$ & 0.5810 \\
\hline dive 2 & $95.50 \pm 51.10$ & $135.50 \pm 42.00$ & 0.0001 \\
\hline Aplhf & $1.15 \pm 0.21$ & $1.21 \pm$ & 0.2680 \\
\hline
\end{tabular}

$\mathrm{CH}=$ corneal hysteresis; $\mathrm{CRF}=$ corneal resistance factor; $\mathrm{DifCH}=$ central corneal thickness; adjusted CH; DifCRF $=$ central corneal thickness-adjusted CRF. ${ }^{*} \mathrm{P}<0.0013$. 
creases in p1 area (26.2\%), p2 area (42.8\%), h2 (37.7\%), and dive2 $(41.9 \%)$ values were observed $(\mathrm{p}<0.001$ for all); however, no significant differences in $\mathrm{CH}, \mathrm{CRF}$, difCH, or difCRF or other waveform-derived parameters were detected at one year postoperatively $(p=0.778, p=0.105$, $\mathrm{p}=0.267, \mathrm{p}=0.121$, respectively). We found positive correlations between $\mathrm{CH}, \mathrm{CRF}, \mathrm{p} 1$ area, p2 area, dive2, h2, p1 area1, p2 area1, and corneal thickness. On the other hand, there was a negative correlation between $\mathrm{CH}, \mathrm{CRF}$, p1 area, dive2, h2, p1 area1, p2 area1, on one hand, and Kmax, elevation anterior, and elevation posterior, on the other. Table 4 presents statistically significant data.

\section{DISCUSSION}

This study evaluated changes in corneal biomechanical properties after accelerated corneal CXL using second-generation waveform-derived parameters. Although no statistically significant difference in $\mathrm{CRF}$ or $\mathrm{CH}$ was observed, significant increases in p1 area, p2 area, h2, and dive2 parameters were observed. To the best of our knowledge, this is the first study to use these parameters in evaluating the effects of accelerated corneal CXL on corneal biomechanics.

Topographic measurements are used to indirectly assess the effects of corneal CXL. It is essential to evaluate the biomechanical changes of the cornea directly in order to evaluate the efficacy of corneal CXL. Currently,

Table 4. Correlation between cornea-related parameters and ORA parameters in patients with keratoconus

\begin{tabular}{|c|c|c|c|c|}
\hline & $\begin{array}{l}\text { Corneal } \\
\text { thickness }\end{array}$ & Kmax & $\begin{array}{c}\text { Elevation } \\
\text { anterior }\end{array}$ & $\begin{array}{l}\text { Elevation } \\
\text { posterior }\end{array}$ \\
\hline $\mathrm{CH}$ & $\begin{array}{l}R=0.7880 \\
P=0.0001\end{array}$ & $\begin{array}{r}R=-0.394 \\
P=0.007\end{array}$ & $\begin{array}{r}R=-0.407 \\
P=0.006\end{array}$ & $\begin{array}{r}R=-0.388 \\
P=0.008\end{array}$ \\
\hline CRF & $\begin{array}{l}R=0.8150 \\
P=0.0001\end{array}$ & $\begin{array}{r}R=-0.530 \\
P<0.001\end{array}$ & $\begin{array}{r}R=-0.494 \\
P=0.001\end{array}$ & $\begin{array}{r}R=-0.478 \\
P=0.001\end{array}$ \\
\hline $\mathrm{P} 1$ area & $\begin{array}{l}R=0.4440 \\
P=0.0020\end{array}$ & $\begin{array}{r}R=-0.322 \\
P=0.031\end{array}$ & $\begin{array}{r}R=-0.360 \\
P=0.015\end{array}$ & $\begin{array}{r}R=-0.432 \\
P=0.003\end{array}$ \\
\hline P2 area & $\begin{array}{l}R=0.3830 \\
P=0.0090\end{array}$ & $\begin{array}{r}R=-0.116 \\
P=0.446\end{array}$ & $\begin{array}{r}R=-0.152 \\
P=0.320\end{array}$ & $\begin{array}{r}R=-0.080 \\
P=0.632\end{array}$ \\
\hline h2 & $\begin{array}{l}R=0.4880 \\
P=0.0010\end{array}$ & $\begin{array}{r}R=-0.409 \\
P=0.005\end{array}$ & $\begin{array}{r}R=-0.436 \\
P=0.003\end{array}$ & $\begin{array}{r}R=-0.466 \\
P=0.001\end{array}$ \\
\hline Dive2 & $\begin{array}{l}R=0.6050 \\
P=0.0001\end{array}$ & $\begin{array}{r}R=-0.344 \\
P=0.021\end{array}$ & $\begin{array}{r}R=-0.520 \\
P<0.001\end{array}$ & $\begin{array}{r}R=-0.551 \\
P<0.001\end{array}$ \\
\hline P1 area1 & $\begin{array}{l}R=0.6990 \\
P=0.0001\end{array}$ & $\begin{array}{r}R=-0.326 \\
P=0.029\end{array}$ & $\begin{array}{r}R=-0.343 \\
P=0.021\end{array}$ & $\begin{array}{r}R=-0.363 \\
P=0.014\end{array}$ \\
\hline P2 area1 & $\begin{array}{l}R=0.7460 \\
P=0.0001\end{array}$ & $\begin{array}{r}R=-0.299 \\
P=0.046\end{array}$ & $\begin{array}{r}R=-0.437 \\
P=0.003\end{array}$ & $\begin{array}{r}R=-0.351 \\
P=0.018\end{array}$ \\
\hline
\end{tabular}

$\mathrm{CH}=$ corneal hysteresis, $\mathrm{CRF}=$ corneal resistance factor. ${ }^{*} \mathrm{P}<0.05$.
ORA is the device used most widely for evaluating in vivo corneal biomechanical properties. Although the biomechanical resistance of the cornea was found to increase after corneal CXL in ex vivo studies ${ }^{(10-12)}$, many studies that used ORA showed that the CRF and the $\mathrm{CH}$ remained unchanged after standard or accelerated $\mathrm{CXL}^{(13,14,21,22)}$. There may be several reasons why $\mathrm{CRF}$ and $\mathrm{CH}$ may not be used to detect biomechanical changes after corneal CXL. First, the biomechanical change may be too small to be detected using the $\mathrm{CRF}$ and $\mathrm{CH}$ measurements. Second, corneal CXL may change the eye's elasticity and viscosity ${ }^{(23)}$. The low $\mathrm{CRF}$ and $\mathrm{CH}$ values observed in keratoconus are caused by changes in proteoglycan and glycosaminoglycan structure ${ }^{(24)}$. Thus, after corneal CXL, new covalent bonds form between collagen fibers ${ }^{(25)}$. In a review, Gatinel suggested that differences between these mechanisms may explain why the CRF and the $\mathrm{CH}$ are insufficient to detect biomechanical changes ${ }^{(26)}$. Accordingly, CXL treatment does not affect corneal biomechanics. Any changes to the corneal detected after CXL have been caused by epithelial wound healing. However, we found a strong positive correlation between corneal thickness and $\mathrm{CRF}$ and $\mathrm{CH}$. After $\mathrm{CXL}$, there was a decrease in $\mathrm{CRF}$ and $\mathrm{CH}$ values and an increase in $\mathrm{DifCH}$ and Dif CRF values. This may indicate that corneal stiffness tends to increase after CXL. However, this trend was not statistically significant. In addition, we found negative correlations between Kmax, elevation anterior, elevation posterior, and ORA parameters. Although linear regression did not reveal any significant difference, the results presented above show clearly that corneal shape and thickness affect ORA parameters.

Therefore, new in vivo methods to detect such biomechanical changes are being studied. One such method is applanation resonance tonometry. Using applanation resonance tonometry, Rehnman et al. ${ }^{(27)}$ showed that $\mathrm{CH}$ increases after conventional corneal CXL. In another study using inverse finite element modeling, corneal stiffness increased after corneal $\mathrm{CXL}^{(28)}$.

The new ORA software provides 37 parameters, allowing for more detailed analysis of the corneal deformation signal waveform. Each parameter describes a morphologic feature of the waveform. Many studies have shown that these parameters are useful in distinguishing between keratoconus and normal patients, as well in identifying early and severe keratoconus ${ }^{(15-17)}$. Spoerl et al. ${ }^{(18)}$ showed a significant increase in p2 area, h2, and dive2 parameters at the one year follow-up after standard CXL treatment. They found that the most prominent 
increase was detected in the p2 area (35\%), with values approaching those observed for healthy corneas. Spoerl et al. ${ }^{(18)}$ suggested that an increase in $\mathrm{p} 2$ area could indicate an improvement in the corneal shear stiffness. The authors argued that this parameter is more successful than CRF and $\mathrm{CH}$ for visualizing changes in corneal biomechanics. In a study by Vinciguerra et al. ${ }^{(14)}$, a significant increase in peak 1 and peak 2 was observed in the first year after conventional corneal CXL. Similarly, in our study, increases in $\mathrm{p} 1$ area, $\mathrm{p} 2$ area, h2, and dive2 were observed after accelerated corneal CXL. The rate of increase in peak 2-related parameters is about $40 \%$, which is more pronounced than the rate of increase in peak 1-related parameters. This ratio is close to the rate of increase reported by authors who performed an ex vivo study (33\%). Increases in stiffness after CXL in human donor cornea were assessed with optical coherence elastography ${ }^{(12)}$.

An increase in the intensity of light reaching the detector manifests as elevation at peaks. After corneal CXL, decreased aberrations, increased homogeneity, and corneal flattening may increase the amount of light reflected from the cornea. Increases in peak height (h2) and the area under the peak ( 1 area, $\mathrm{p} 2$ area) may be related to the increase in reflected light. Hallahan et al. ${ }^{(19)}$ followed 24 eyes for three months after conventional corneal CXL, and no significant difference was found in any of the 37 parameters investigated. In this study, the small sample size and short follow-up (three months) prevented the measurements of any increase in biomechanical resistance after corneal CXL. Notably, epithelial remodeling during the first few months postoperatively may alter corneal biomechanics and cause light scattering throughout the cornea, which may lead to inaccurate measurements ${ }^{(14,29)}$. In a study by Vinciguerra et al. ${ }^{(14)}$, increases in peak 1 and peak 2 were not significant during the early postoperative period but became significant at six months.

Although the new second-generation waveform parameters are not real measured biomechanical parameters, the signal provided by biomechanical waveform analysis provides a morphologically unique fingerprint for each eye and may contain valuable clinical informa$\operatorname{tion}^{(30)}$. Therefore, these parameters could be a sensitive indicator of corneal morphology. Waveform-derived parameters may be considered to be more sensitive than $\mathrm{CRF}$ and $\mathrm{CH}$ in visualizing changes in corneal biomechanics after CXL.
Clinical studies have shown that corneal CXL is effective in improving visual acuity, reducing corneal steepness, and stabilizing keratoconus. Changes in visual acuity and corneal topography caused by accelerated CXL treatment have similarly been reported by other studies in the literature ${ }^{(31,32)}$. Thus, the accelerated corneal CXL protocol may have succeeded in discontinuing and partially reversing the progression of keratoconus.

In conclusion, parameters p1 area, p2 area, h2, and dive2 appear to be more sensitive than $\mathrm{CRF}$ and $\mathrm{CH}$ for detecting corneal biomechanical changes after accelerated corneal CXL. Therefore, these parameters may help to determine which CXL method is more effective for increasing biomechanical resistance of the cornea.

\section{REFERENCES}

1. Rabinowitz YS. Keratoconus. Surv Ophthalmol. 1998;42(4):297-319.

2. Touboul D, Bénard A, Mahmoud AM, Gallois A, Colin J, Roberts C). Early biomechanical keratoconus pattern measured with an ocular response analyzer: curve analysis. J Cataract Refract Surg. 2011;37(12):2144-50.

3. Wollensak G, Spoerl E, Seiler T. Riboflavin/ultraviolet-a-induced collagen crosslinking for the treatment of keratoconus. Am J Ophthalmol. 2003;135(5):620-7.

4. Kymionis GD, Grentzelos MA, Kankariya VP, Liakopoulos DA, Portaliou DM, Tsoulnaras Kl, et al. Safety of high-intensity corneal collagen crosslinking. J Cataract Refract Surg. 2014;40(8):1337-40.

5. Schumacher S, Oeftiger L, Mrochen M. Equivalence of biomechanical changes induced by rapid and standard corneal cross-linking, using riboflavin and ultraviolet radiation. Invest Ophthalmol Vis Sci. 2011;52(12):9048-52.

6. Gatzioufas Z, Richoz O, Brugnoli E, Hafezi F. Safety profile of high-fluence corneal collagen cross-linking for progressive keratoconus: preliminary results from a prospective cohort study. J Refract Surg. 2013;29(12):846-8.

7. Luce DA. Determining in vivo biomechanical properties of the cornea with an ocular response analyzer. J Cataract Refract Surg. 2005; 31(1):156-62.

8. Fontes BM, Ambrósio R Jr, Velarde GC, Nosé W. Ocular response analyzer measurements in keratoconus with normal central corneal thickness compared with matched normal control eyes. J Refract Surg. 2011;27(3):209-15.

9. Touboul D, Roberts C, Kérautret J, Garra C, Maurice-Tison S, Saubusse E, et al. Correlations between corneal hysteresis, intraocular pressure, and corneal central pachymetry. J Cataract Refract Surg. 2008;34(4):616-22.

10. Wollensak G, Spoerl E, Seiler T. Stress-strain measurements of human and porcine corneas after riboflavin-ultraviolet-A-induced cross-linking. J Cataract Refract Surg. 2003;29(9):1780-5.

11. Wollensak G, lomdina E. Long-term biomechanical properties of rabbit cornea after photodynamic collagen crosslinking. Acta Ophthalmol. 2009;87(1):48-51.

12. Ford MR, Sinha Roy A, Rollins AM, Dupps WJ Jr. Serial biomechanical comparison of edematous, normal, and collagen crosslinked human donor corneas using optical coherence elastography. J Cataract Refract Surg. 2014;40(6):1041-7. 
13. Goldich Y, Barkana Y, Morad Y, Hartstein M, Avni I, Zadok D. Can we measure corneal biomechanical changes after collagen cross-linking in eyes with keratoconus?-a pilot study. Cornea. 2009; 28(5):498-502.

14. Vinciguerra P, Albè E, Mahmoud AM, Trazza S, Hafezi F, Roberts C). Intra- and postoperative variation in ocular response analyzer parameters in keratoconic eyes after corneal cross-linking. J Refract Surg. 2010;26(9):669-76.

15. Luz A, Lopes B, Hallahan KM, Valbon B, Ramos I, Faria-Correia F, et al. Enhanced Combined Tomography and Biomechanics Data for Distinguishing Forme Fruste Keratoconus. J Refract Surg. 2016; 32(7):479-94.

16. Luz A, Lopes B, Hallahan KM, Valbon B, Fontes B, Schor P, et al. Discriminant value of custom ocular response analyzer waveform derivatives in forme fruste keratoconus. Am J Ophthalmol. 2016; 164:14-21.

17. Ventura BV, Machado AP, Ambrósio R Jr, Ribeiro G, Araújo LN, Luz A, et al. Analysis of waveform-derived ORA parameters in early forms of keratoconus and normal corneas. J Refract Surg. 2013; 29(9):637-43.

18. Spoerl E, Terai N, Scholz F, Raiskup F, Pillunat LE. Detection of biomechanical changes after corneal cross-linking using Ocular Response Analyzer software. J Refract Surg. 2011;27(6):452-7.

19. Hallahan KM, Rocha K, Roy AS, Randleman JB, Stulting RD, Dupps W] Jr. Effects of corneal cross-linking on ocular response analyzer waveform-derived variables in keratoconus and postrefractive surgery ectasia. Eye Contact Lens. 2014;40(6):339-44.

20. Galletti JG, Pförtner T, Bonthoux FF. Improved keratoconus detection by ocular response analyzer testing after consideration of corneal thickness as a confounding factor. J Refract Surg. 2012; 28(3):202-8.

21. Hashemi H, Fotouhi A, Miraftab M, Bahrmandy H, Seyedian MA, Amanzadeh K, et al. Short-term comparison of accelerated and standard methods of corneal collagen crosslinking. J Cataract Refract Surg. 2015;41(3):533-40.

22. Tomita M, Mita M, Huseynova T. Accelerated versus conventional corneal collagen crosslinking. J Cataract Refract Surg. 2014;40(6): 1013-20.
23. Glass DH, Roberts C), Litsky AS, Weber PA. A viscoelastic biomechanical model of the cornea describing the effect of viscosity and elasticity on hysteresis. Invest Ophthalmol Vis Sci. 2008;49(9): 3919-26.

24. Akhtar S, Bron AJ, Salvi SM, Hawksworth NR, Tuft SJ, Meek KM. Ultrastructural analysis of collagen fibrils and proteoglycans in keratoconus. Acta Ophthalmol. 2008;86(7):764-72.

25. Spoerl E, Wollensak G, Seiler T. Increased resistance of crosslinked cornea against enzymatic digestion. Curr Eye Res. 2004;29(1):35-40.

26. Gatinel D. Reevaluating the effectiveness of corneal collagen cross-linking and its true biomechanical effect in human eyes. Int J Keratoconus Ectatic Corneal Dis. 2017;6(1):34-41.

27. Beckman Rehnman J, Behndig A, Hallberg P, Lindén C. Increased corneal hysteresis after corneal collagen crosslinking: a study based on applanation resonance technology. JAMA Ophthalmol. 2014;132(12):1426-32.

28. Sinha Roy A, Rocha KM, Randleman JB, Stulting RD, Dupps WJ Jr. Inverse computational analysis of in vivo corneal elastic modulus change after collagen crosslinking for keratoconus. Exp Eye Res. 2013;113:92-104. Erratum in: Exp Eye Res. 2016;145:472.

29. Koç M, Uzel MM, Koban Y, Durukan I, Tekin K, Ylmazbaş P. Comparison of results of accelerated corneal cross-linking with hypo-osmolar riboflavin solution performed on corneas thicker and thinner than $400 \mu \mathrm{m}$. Cornea. 2016;35(2):151-6.

30. Franco S, Lira M. Biomechanical properties of the cornea measured by the Ocular Response Analyzer and their association with intraocular pressure and the central corneal curvature. Clin Exp Optom. 2009;92(6):469-75.

31. Elbaz U, Shen C, Lichtinger A, Zauberman NA, Goldich Y, Chan $\mathrm{CC}$, et al. Accelerated $\left(9-\mathrm{mW} / \mathrm{cm}^{2}\right)$ corneal collagen crosslinking for keratoconus-A 1-year follow-up. Cornea. 2014;33(8):769-73.

32. Koc M, Uzel MM, Tekin K, Kosekahya P, Ozulken K, Yilmazbas P. Effect of preoperative factors on visual acuity, corneal flattening, and corneal haze after accelerated corneal crosslinking. J Cataract Refract Surg. 2016;42(10):1483-9. 